\title{
Oral Drops, Granules for Solution Dosage
} Form

National Cancer Institute

\section{Source}

National Cancer Institute. Oral Drops, Granules for Solution Dosage Form. NCI

Thesaurus. Code C149708.

Solid preparation consisting of granules intended to be dissolved in the specified liquid to obtain an oral drops solution. 